\title{
A Role of the Ubiquitin-Proteasome System in Neuropathic Pain
}

\author{
Andrew Moss, ${ }^{1}$ Gordon Blackburn-Munro, ${ }^{1}$ Emer M. Garry, ${ }^{1}$ James A. Blakemore, ${ }^{1}$ Tracey Dickinson, ${ }^{1}$ \\ Roberta Rosie, ${ }^{1}$ Rory Mitchell, ${ }^{2}$ and Susan M. Fleetwood-Walker ${ }^{1}$ \\ ${ }^{1}$ Department of Preclinical Veterinary Sciences, The Royal (Dick) School of Veterinary Studies, The University of \\ Edinburgh, Summerhall, Edinburgh EH9 1QH, United Kingdom, and ${ }^{2}$ Medical Research Council Membrane and Adapter \\ Proteins Cooperative Group and Membrane Biology Group, Division of Biomedical and Clinical Laboratory Sciences, \\ University of Edinburgh, Edinburgh EH8 9XD, United Kingdom
}

Neuropathic pain (characterized by hyperalgesia and allodynia to mechanical and thermal stimuli) causes cellular changes in spinal dorsal horn neurons, some of which parallel those in synaptic plasticity associated with learning. Ubiquitin C-terminal hydrolase (UCH) appears to play a key role in longterm facilitation in Aplysia. The cooperation of $\mathrm{UCH}$ with the proteolytic enzyme complex known as the proteasome is required for the degradation of a number of signaling molecules within the cell that may remove normal restraints on synaptic plasticity. We have used electrophysiology, in situ hybridization histochemistry, semiquantitative RT-PCR, Western blotting, and in vivo behavioral reflex analysis to investigate the ubiquitinproteasome system in a model of neuropathic pain. In neuropathic animals, ionophoretic application of selective proteasome inhibitors attenuated dorsal horn neuron firing evoked by normally innocuous brush or cold stimuli and by noxious mus-

After damage to the distal parts of primary afferent neurons that transmit nociceptive information, their abnormal and repetitive firing is known to induce a state of neuronal hyperexcitability within the spinal dorsal horn, referred to as "central sensitization." A characteristic consequence of this is the development of accentuated pain-related behaviors, reflecting hyperalgesia and allodynia in response to thermal and mechanical stimulation. In animal models of neuropathic pain, these are associated with various neurochemical and neuroanatomical changes occurring within the nociceptive pathway itself (Hökfelt et al., 1994; Woolf et al., 1995; Chung et al., 1996; Cameron et al., 1997).

A number of the changes associated with central sensitization in response to sustained nociceptive activation are similar to those observed in animal models of synaptic plasticity, such as long-term potentiation (LTP) in the mammalian hippocampus. Both LTP and central sensitization trigger activity-dependent changes in neuronal excitability via mechanisms including the post-translational modification of membrane-bound proteins such

\footnotetext{
Received June 4, 2001; revised Nov. 20, 2001; accepted Nov. 27, 2001.

This work was supported by The Wellcome Trust (S.F.-W.) and by The Medical Research Council and the University of Edinburgh for the award of Studentships (A.M. and E.G., respectively). We thank staff at Wellcome Animal Research Unit and Medical Faculty Animal Area facilities for animal husbandry.

Correspondence should be addressed to Dr. S. M. Fleetwood-Walker, Department of Preclinical Veterinary Sciences, University of Edinburgh, Edinburgh EH9 1QH, UK. E-mail: sfw@vet.ed.ac.uk.

G. Blackburn-Munro's present address: NeuroSearch A/S, 93 Pederstrupvej, \#DK-2750, Ballerup, Denmark.

T. Dickinson's present address: Department of Pharmacology, Quintiles Scotland Ltd., Heriot-Watt University Research Park, Riccarton, Edinburgh EH14 4AP, UK Copyright (C) 2002 Society for Neuroscience $0270-6474 / 02 / 221363-10 \$ 15.00 / 0$
}

tard oil stimuli. In control animals, only mustard oil-evoked responses were inhibited. Intrathecal administration of proteasome inhibitors attenuated hyperalgesia and allodynia in neuropathic rats. Expression of UCH-L1 (a rat homolog of Aplysia neuronal $\mathrm{UCH}$ and of the human $\mathrm{UCH}-\mathrm{L} 1$, also known as PGP 9.5) and its mRNA were selectively increased within the ipsilateral dorsal horn of neuropathic rats, supporting the idea of a role for the ubiquitin-proteasome system in nociceptive processing. Proteasome inhibitors selectively attenuate allodynic and hyperalgesic responses in neuropathic pain, with some reduction in normal nociceptive, but not non-nociceptive responses, and potentially represent a novel therapeutic strategy for neuropathic pain.

Key words: neuropathic pain; spinal cord; proteasome; ubiquitination; hyperalgesia; allodynia

as the NMDA receptor. Downstream targets common to both processes may include $\mathrm{Ca}^{2+} /$ calmodulin-dependent kinases, protein kinase $\mathrm{C}(\mathrm{PKC})$, protein kinase $\mathrm{A}$ (PKA), and nitric oxide synthase (Bliss and Collingridge, 1993; Mayer et al., 1999). A partially analogous process of long-term facilitation (LTF) of synaptic responses occurs in Aplysia sensory pathways, where a number of the molecular changes underlying LTF are evoked in common by sensory neuron injury (Walters and Ambron, 1995). In the LTF model, sustained sensory neuron activation induces the activation of PKA with the dissociation of PKA regulatory subunits and the translocation of the constitutively active free catalytic subunits to the cell nucleus (Chain et al., 1999). The ubiquitin-proteasome system appears to play a vital role in the regulation of PKA activity by degrading the regulatory subunits of PKA, which normally maintain PKA in an inactive state. Stimulus-induced degradation of PKA regulatory subunits is thus thought to lead to persistent activation of the kinase and maintenance of the synapse in a facilitated state (Greenberg et al., 1987; Chain et al., 1999).

The ubiquitin-proteasome system is a major non-lysosomal proteolytic pathway that degrades diverse cellular proteins, including a number of proteins with important roles in the regulation of cell growth or function (Coux et al., 1996; Rolfe et al., 1997; Hershko and Ciechanover, 1998). For example, protein degradation by this pathway is important for the control of PKA activity (Hegde et al., 1993). The functional activity of the proteasome is enhanced by the UCH family of isopeptidases, which appear to play a crucial role in maintaining activity by preventing 
accumulation of inhibitory polyubiquitin chains (Wilkinson, 1997). The present study explores the contribution made by the ubiquitin-proteasome system to the central sensitization, hyperalgesia, and allodynia that characterize intractable neuropathic pain.

\section{MATERIALS AND METHODS}

\section{Chronic constriction injury to the sciatic nerve}

All experiments were performed in accordance with the United Kingdom Animals (Scientific Procedures) Act, 1986. Adult male Wistar rats (200-350 gm, Charles River, Kent, UK) were anesthetized with sodium pentobarbital (Sagatal 0.06 ml/100 gm, i.p.; Rhône Merieux, Essex, UK) and supplemented with halothane/ $\mathrm{O}_{2}$ (Zeneca, Cheshire, UK). Under aseptic conditions, the right sciatic nerve was exposed proximal to the trifurcation, at a mid-thigh level, and four chromic cat gut ligatures (4:0; Ethicon, Edinburgh, UK) were tied to loosely constrict the nerve [chronic constriction injury (CCI)], as viewed under $40 \times$ magnification (Bennett and $\mathrm{Xie}, 1988)$. The overlying muscle and skin were closed with sutures (4:0; Ethicon), and the animals were allowed to recover for $72 \mathrm{hr}$ before reflex testing recommenced. Sham-operated animals underwent the same surgical procedure, but no ligatures were placed around the nerve.

\section{Behavioral tests}

Behavioral testing was performed before surgery to establish a baseline for comparison with post-surgical values. Inspections were made regularly for signs of autotomy, which was rarely observed. CCI animals were always assessed for the presence of thermal hyperalgesia, cold, and mechanical allodynia before being used for further study in other tests. Only in occasional cases did reflex sensitization fail to develop, and in those examples technical factors appeared to be responsible. The following behavioral reflex tests were performed as described in detail previously (Blackburn-Munro et al., 1999; Dickinson et al., 1999). Thermal hyperalgesia was monitored using noxious radiant heat $\left(30-55^{\circ} \mathrm{C}\right.$; Hargreaves' thermal device, Linton Instruments, Diss, UK) applied to the mid-plantar glabrous surface of the hindpaw. The withdrawal response latency was characterized as a brief paw flick recorded to the nearest 0.1 sec; a standard cutoff latency of $20 \mathrm{sec}$ prevented tissue damage.

Mechanical allodynia was measured as the threshold for paw withdrawal in response to graded mechanical stimuli applied to the midplantar glabrous surface of the hindpaw using calibrated von Frey filaments (Stoelting, Wood Dale, IL). Threshold was defined as the pressure (force per unit area) that caused foot withdrawal five times in every 10 applications, repeated at $1-2 \mathrm{sec}$ intervals. The pressure applied to the hindlimb by the von Frey filaments is calibrated as force (milliNewtons) divided by the area over which it is applied (millimeters squared).

To detect the presence of cold allodynia, rats were placed in a perspex box with an elevated aluminum floor covered with iced water, sufficient to immerse both glabrous and hairy skin of the hindpaw $\left(3-4^{\circ} \mathrm{C}\right)$ (Bennett and Xie, 1988). Once placed in the box, rats were allowed $10 \mathrm{sec}$ to acclimatize. The number of seconds the animal raised its hindpaw above the water over a $20 \mathrm{sec}$ period was recorded. This was repeated four times at $10 \mathrm{~min}$ intervals to establish a mean suspended paw elevation time (SPET) for each rat. Animals determined as being at the peak of neuropathy, 12-14 d after CCI surgery, were then used in the experiments described below.

\section{Intrathecal drug treatment}

The effects of intrathecal administration of the selective proteasome inhibitors MG-132 (Rock et al., 1994) and epoxomicin (Sin et al., 1999) on behavioral reflex responses were examined. Before determining the effects of these inhibitors, baseline measurements were recorded in rats [normal (i.e., naive), $n=8$; neuropathic, $n=26$ ] both before and at the peak of neuropathy. A minimum of four measurements were made for each test session, for each sensory test. Rats were anesthetized briefly with halothane $/ \mathrm{O}_{2}$ and injected intrathecally at the L5 level of the spinal cord with $5 \mathrm{nmol}$ of MG-132 or $0.75 \mathrm{nmol}$ of epoxomicin in saline with $0.5 \%$ dimethylformamide $(50 \mu \mathrm{l})$, using a 25 gauge needle microsyringe. Injection of vehicle had no discernable effect on behavioral reflexes. The identity of the drug was concealed from the experimenter to eliminate bias, and dye injections (Pontamine Sky Blue) were performed in separate experiments to define the correct site of injection. Testing began 15 min after injection (a delay to allow for full recovery of reflex function after anesthesia) and was performed at $5 \mathrm{~min}$ (thermal hyperalgesia and mechanical allodynia) or 10 min intervals (cold allodynia). Testing continued until recovery to pre-injection values.

\section{Single neuron electrophysiological recording experiments}

After induction of anesthesia with halothane $/ \mathrm{O}_{2}$, rats (normal, $n=8$; sham, $n=4$; neuropathic, $n=11$ ) underwent jugular vein and tracheal cannulations. Anesthesia was then maintained using intravenous $\alpha$-chloralose $(60 \mathrm{mg} / \mathrm{kg})$ and urethane $(1.2 \mathrm{mg} / \mathrm{kg})$. Supplementary doses of $\alpha$-chloralose were given as required. Core temperature was maintained at $37-38^{\circ} \mathrm{C}$, and $\mathrm{O}_{2}(0.1 \mathrm{l} / \mathrm{min})$ was passed over the end of the cannula to enrich the inspired air. A laminectomy (segments L3-L6) was performed, as described previously (Blackburn-Munro and FleetwoodWalker, 1997). Extracellular recordings were made from single, multireceptive neurons (laminas III-V), ipsilateral to the nerve injury in neuropathic animals and bilaterally in unoperated, naïve control rats via the central barrel ( $4 \mathrm{M} \mathrm{NaCl}, \mathrm{pH} 4.0-4.5)$ of a multibarreled glass microelectrode (tip size $4-5 \mu \mathrm{m}$ ). One side barrel contained $1 \mathrm{M} \mathrm{NaCl}$, $\mathrm{pH} 4.5$, for automatic current balancing using a Neurophore BH2 Ionophoresis System (Medical Systems Corporation). The remaining barrels contained drugs for ionophoretic application of drug: the selective proteasome inhibitors lactacystin (Fenteany et al., 1995) and MG-132 (both in $0.5 \%$ aqueous dimethylformamide, $\mathrm{pH} 4.5$, at concentrations of 500 and $200 \mu \mathrm{M}$, respectively; Biomol, Plymouth Meeting, PA). Drugs were ejected using positive currents of 5-60 $\mathrm{nA}$, and a retention current of $-12 \mathrm{nA}$ was applied to each side barrel when not in use to minimize drug leakage. The resistance of the side barrels was monitored regularly, and electrodes with resistance values in excess of $45 \mathrm{M} \Omega$ were rejected.

The effects of the inhibitors were examined on evoked responses of neurons to sensory stimulation in both naive and neuropathic animals. Sustained activation of neurons was obtained by the following stimuli, described in detail elsewhere (Dickinson et al., 1999): (1) a rotating motorized innocuous brush for low threshold mechanical stimulation and (2) an intense cold stimulus provided by a Peltier device $\left[5^{\circ} \mathrm{C}\right.$ for $10 \mathrm{sec}$, from $32^{\circ} \mathrm{C}$ (ramp rate $5^{\circ} \mathrm{C} / \mathrm{sec}$ ), over a surface area of $1 \mathrm{~cm}^{2}$; Medical Instruments, Yale University, New Haven, CT]. The stimuli were repeated every 1-2 min to give reproducible peaks of activity. (3) Topical application of the C-fiber-selective chemical algogen, mustard oil [allyl isothiocyanate (Aldrich Chemical Company), 7.5\% solution in paraffin oil, applied up to seven times at 5 min intervals].

Drugs were ejected ionophoretically in a step-wise manner (usually in increments of $10 \mathrm{nA}$, over a range of 5-60 nA) every 1-2 min, until clear effects on the neuronal firing rate were observed; if none was observed by $60 \mathrm{nA}$ after $2 \mathrm{~min}$ duration, the drug application was terminated. For the majority of neurons, both drugs were tested on responses to all three sensory stimuli.

Action potential discrimination enabled data to be digitized and downloaded onto a computer to give a record of cell firing rate measured as action potentials per second. After subtraction of the "background" activity, the firing rate after drug application was expressed as the percentage change from control responses of the neuron before drug application.

\section{Determination of levels of $m R N A$ for ubiquitin $C$-terminal hydrolase- $L 1$}

$m R N A$ analysis by RT-PCR. Relevant segments of spinal cord were dissected into ipsilateral and contralateral sides and immersed in liquid nitrogen. Total RNA was extracted using Trizol (Invitrogen, Paisley, UK) according to the manufacturer's guidelines. The cDNAs were obtained using SuperScript II Moloney's murine leukemia virus reverse transcriptase (Invitrogen) according to the manufacturer's protocol. Briefly, $5 \mu \mathrm{g}$ DNase-treated total RNA was added to reverse transcription buffer ( $50 \mathrm{~mm}$ Tris- $\mathrm{Cl}, \mathrm{pH} 8.3,75 \mathrm{~mm} \mathrm{KCl}, 5 \mathrm{mM} \mathrm{MgCl}_{2}$ ) containing $17 \mathrm{U}$ RNAsin (Invitrogen), $10 \mathrm{~mm}$ dNTPs, and $0.5 \mu \mathrm{M}$ poly $(\mathrm{dT})_{12-18}$ primer. Semiquantitative PCR was performed for rat ubiquitin C-terminal hydrolase-L1 (UCH-L1)/PGP 9.5 homolog (Wilkinson et al., 1989; Kajimoto et al., 1992) and for the metabolic housekeeping enzyme, glyceraldehyde-3-phosphodehydrogenase (GAPDH). An excess of UCH amplification primers (forward: 5'-GCT GCT GCT GTT TCC CCT CAC; reverse: 5'-AGA CCT TGG CGG CAT CCT G) (MWG Biotech) ( $0.5 \mu \mathrm{M}$ final concentration), supplemented with 5 U Taq DNA polymerase (Invitrogen), and $2 \mu \mathrm{l}$ of the first-strand reaction mix, were used for each amplification. PCR cycling conditions were as follows: 1 cycle of 5 min at $94^{\circ} \mathrm{C}$, and 22 cycles of $45 \mathrm{sec}$ at $94^{\circ} \mathrm{C}, 30 \mathrm{sec}$ at $56^{\circ} \mathrm{C}, 1 \mathrm{~min}$ at $72^{\circ} \mathrm{C}$. This resulted in a linear amplification of the 324 base pair (bp) UCH-L1 DNA fragment, as quantified by direct measurements of fluorescence of 
the amplified fragments using a digital imaging system (UVP) and Scan-Analysis software (Biosoft). A second round of PCR was performed in the presence of $3^{\prime}-\mathrm{NH}_{2}$-linked GAPDH primers in an 8:2 molar ratio with standard GAPDH primers: forward, $5^{\prime}$-GGC AGC CCA GAA CAT CAT CC; reverse, 5'-CAG CCC CAG CAT CAA AGG TG. This produced levels of fluorescence comparable to the $324 \mathrm{bp} \mathrm{UCH-L1}$ PCR fragment using PCR conditions identical to those above.

After coamplification of the target UCH-L1 and GAPDH sequences, equal amounts of reaction products were analyzed by gel electrophoresis in a $2 \%(\mathrm{w} / \mathrm{v})$ agarose gel containing $0.5 \mu \mathrm{g} / \mathrm{ml}$ ethidium bromide. Relative levels of UCH-L1 mRNA expression were calculated by expressing relative levels of UCH-L1 mRNA fluorescence as a percentage of GAPDH mRNA fluorescence.

In situ hybridization histochemistry. Neuropathic animals and agematched naïve controls were deeply anesthetized with halothane $/ \mathrm{O}_{2}(4 \%$ for induction and maintenance), and a laminectomy (L3-L6) was performed for spinal cord removal. Tissue was mounted on a cryostat chuck (OCT Embedding Matrix, CellPath Ltd., Wales, UK) and snap frozen in isopentane (BDH, Poole, UK) at -40 to $-45^{\circ} \mathrm{C}$. Frozen transverse sections of spinal cord $(10 \mu \mathrm{m})$ were taken at $-19^{\circ} \mathrm{C}$ in a cryostat and thaw-mounted onto poly-lysine-coated microscope slides (BDH).

Two oligonucleotides (synthesized by Oswel DNA Service) complementary and specific to nucleotides $299-333$ and $658-693$ of rat UCH-L1 mRNA were used (Kajimoto et al., 1992). The oligonucleotides were 3' end-labeled with deoxyadenosine $\alpha\left[{ }^{35} \mathrm{~S}\right]$-triphosphate (specific activity $<1250 \mathrm{Ci} / \mathrm{mol}$; DuPont NEN) using terminal deoxynucleotidyl transferase (Promega). In situ hybridization histochemistry was performed using methodology described previously (Blackburn-Munro and Fleetwood-Walker, 1999). Controls used to demonstrate specificity of the respective oligonucleotide consisted of (1) pretreating sections with RNase A ( $1 \mathrm{mg} / \mathrm{ml}$; Sigma, Poole, UK) for $1 \mathrm{hr}$ before hybridization and (2) coincubation of the ${ }^{35} \mathrm{~S}$-labeled oligonucleotide in the hybridization medium with a 100 -fold excess of unlabeled oligonucleotide.

\section{Image analysis}

Cell counts. The number of cells positively hybridized for UCH-L1 within lateral and midway between lateral and medial ("mediolateral") locations of laminas I-V was calculated at $40 \times$ magnification (total grid area $175 \times$ $175 \mu \mathrm{m})$. Cells were considered to be positively labeled if the silver grains showed a dense pattern around the nucleus and were fivefold denser than a typical nonexpressing cell within the same field area or background levels. The total number of positively hybridized cells was determined for each spinal cord section ( $n=10$ sections), and these values were used to calculate the mean number of positively hybridized cells per unit area, in the lumbar spinal segments L3-L6 (naïve, $n=4$; neuropathic, $n=4$ ).

Silver grain counting. To assess any changes in the relative expression of UCH-L1 mRNA after chronic constriction injury, the mean silver grain density per positively labeled cell was measured using Image 1.44 software (Improvision) with video input from a charge-coupled device camera (Sony, Tokyo, Japan) mounted on a Zeiss Axioscope microscope $(40 \times$ magnification). For each section, counts were made both ipsilateral and contralateral to the nerve injury in lateral and medial zones. A minimum of five positively hybridized cells was counted in each region. A pixel count was obtained, which was converted to silver grain number via a predetermined calibration procedure. The mean number of silver grains per cell was calculated for each section ( $n=10$ sections). Then the mean number of silver grains per cell could be calculated. In total, 500 positively hybridized cells were counted within one side of the spinal dorsal horn for each animal.

Western blot analysis of the expression of ubiquitin C-terminal hydrolase. Hemisected L3-L6 spinal cord samples (naive, $n=4$; neuropathic, $n=$ 4; sham, $n=4$ ) were homogenized into standard Laemmli buffer and denatured at $100^{\circ} \mathrm{C}$ for $5 \mathrm{~min}$. Extracts were separated by electrophoresis on precast $10 \%$ polyacrylamide gels (Bio-Rad, Hemel Hempstead, UK), transferred to polyvinylidene difluoride membrane, and blocked overnight at $4^{\circ} \mathrm{C}$ in $4 \%$ Marvel, $0.1 \%$ Tween 20 . Blots were probed with primary antibody to UCH-L1/PGP 9.5 (Affiniti; 1:5000) or GAPDH (Chemicon; 1:750) and detected by peroxidase-linked secondary antibody enhanced chemiluminescence.

Ex vivo PKA activity assays. After lumbar laminectomy under anesthesia, rats, (naïve, $n=3$; neuropathic, $n=3$ ) were treated by topical application of agents to the dorsal surface of the spinal cord. Epoxomicin $(15 \mu \mathrm{M}), \mathrm{MG}-132(100 \mu \mathrm{M})$, or vehicle $(0.5 \%$ dimethylformamide in saline) was applied in a volume of $500 \mu \mathrm{l}$ for $1 \mathrm{hr}$ before rapid removal of segments L3-L6 to cold buffer on ice. cAMP-evoked PKA enzymatic activity and constitutive activity (thought to reflect PKA previously activated in situ) were measured by the following procedure, a modification of those of Roskoski (1983) and Corbin (1983). Hemisected spinal cord samples were rapidly homogenized on ice in $20 \mathrm{~mm} \mathrm{Na}$ HEPES, $\mathrm{pH}$ 7.5 , with $5 \%$ glycerol, $0.25 \%$ BSA, 1 mM EGTA, 1 mm dithiothreitol, 1 $\mathrm{mM}$ 4-(2-aminoethyl) benzene sulfonyl fluoride (Alexis Corporation, Nottingham, UK), $2 \mu \mathrm{g} / \mathrm{ml}$ aprotinin, $10 \mu \mathrm{g} / \mathrm{ml}$ leupeptin, $2 \mu \mathrm{g} / \mathrm{ml}$ pepstatin, $50 \mu \mathrm{g} / \mathrm{ml}$ soybean trypsin inhibitor, $25 \mathrm{~mm} \mathrm{Na}$ $\beta$-glycerophosphate, $1 \mathrm{~mm} \mathrm{Na}$ orthovanadate, $1 \mathrm{~mm} \mathrm{NaF}, 1 \mu \mathrm{M}$ calyculin A, $1 \mu \mathrm{M}$ cypermethrin (Calbiochem, Nottingham, UK), and $500 \mu \mathrm{M}$ isobutyl methylxanthine. All reagents were from Sigma unless indicated otherwise. Aliquots of homogenate were incubated for $10 \mathrm{~min}$ at $30^{\circ} \mathrm{C}$ (linear range of assay) with $100 \mu \mathrm{M}$ kemptide as substrate, $100 \mu \mathrm{M}$ ATP (with $\left[{ }^{33} \mathrm{P}\right] \alpha$-ATP to $0.2 \mu \mathrm{Ci}$ per tube; DuPont NEN, Dreiech, Germany), $10 \mathrm{mM} \mathrm{MgCl}_{2}$, and $10 \mu \mathrm{M} \mathrm{cAMP}$ and/or $1 \mu \mathrm{M} \mathrm{PKI}_{6-22}$ amide (Calbiochem) as appropriate. Assays were terminated with cold TCA (to $10 \%$ ), centrifugation, and spotting of the supernatant onto P81 phosphocellulose paper. Samples were washed extensively in $75 \mathrm{~mm} \mathrm{H}_{3} \mathrm{PO}_{4}$ and dried before scintillation counting. Positive controls were performed with purified bovine heart PKA catalytic subunit, and each homogenate was assayed in parallel for cAMP-evoked activity (in the absence or presence of $\mathrm{PKI}_{6-22}$ amide), constitutive activity (in the absence or presence of $\mathrm{PKI}_{6-22}$ amide), and zero time incubation blanks. Authentic ( $\mathrm{PKI}_{6-22}$ amide-sensitive) PKA-activity was always $86-97 \%$ of the recorded activity for constitutive and cAMP-evoked conditions, and zero time blanks were always $<2 \%$ of total activity.

Subcellular distribution of specific $\left[{ }^{3} \mathrm{H}\right]$ phorbol dibutyrate binding sites. After topical application of drugs and homogenization in the same ice-cold medium as for PKA assays above, spinal cord (L3-L6) homogenates were assayed for membrane/cytosol content of specific $\left[{ }^{3} \mathrm{H}\right]$ phorbol dibutyrate binding sites as described previously (Johnson et al., 1996). Briefly, after centrifugation at $12,000 \times g$ for $20 \mathrm{~min}$, the membrane pellet was resuspended in $50 \mathrm{~mm}$ Tris $\mathrm{HCl}, \mathrm{pH} 7.4$, with $4 \mathrm{mg} / \mathrm{ml}$ fatty acid-free BSA (Tris BSA), and aliquots were incubated (30 $\mathrm{min}$ at $\left.37^{\circ} \mathrm{C}\right)$ with $5 \mathrm{~nm}\left[{ }^{3} \mathrm{H}\right]$ phorbol 12,13 -dibutyrate $(0.03 \mu \mathrm{Ci}$ per tube; DuPont NEN) with or without $10 \mu \mathrm{M}$ unlabeled phorbol dibutyrate to define nonspecificity. Aliquots of the supernatant cytosolic fraction were added to Tris BSA containing $1 \mathrm{mM} \mathrm{CaCl}_{2}, 10 \mathrm{mM} \mathrm{MgCl}_{2}$, and $0.5 \mathrm{mg} / \mathrm{ml}$ sonicated phosphatidylserine (Sigma) before equivalent incubation with ligand. Bovine $\gamma$-globulin (to $0.6 \mathrm{mg} / \mathrm{ml}$ ) and polyethylene glycol- 8000 (to $20 \%$ ) in $50 \mathrm{~mm}$ Tris $\mathrm{HCl}$ were added to cytosol samples and incubated for $20 \mathrm{~min}$ at $4{ }^{\circ} \mathrm{C}$ to precipitate proteins. After centrifugation at $12,000 \times$ $g$ for $20 \mathrm{~min}$, all samples were aspirated, and radioactivity in the pellets was measured by liquid scintillation counting.

\section{RESULTS}

\section{Behavioral reflex studies}

Neuropathic animals showed behavioral alterations after CCI that were consistent with previous data from our laboratory (Blackburn-Munro and Fleetwood-Walker, 1999; Dickinson et al., 1999). Development of neuropathic behaviors became measurable at $8 \mathrm{~d}$ after surgery, with peak changes at 12-14 d. Most experiments were performed using CCI animals taken at 12-14 d after surgery, although some samples for time course studies were taken at 4 and $8 \mathrm{~d}$.

\section{Sensory responses of single dorsal horn neurons: application of inhibitors of the proteasome complex}

Most of the recorded neurons were multi-receptive, responding to both innocuous and noxious stimuli. They were estimated to be located within dorsal horn laminas III-V at depths of $\sim 200-700$ $\mu \mathrm{m}$ from the surface of the spinal cord that were measured using electrode contact at the dorsal surface and dye spot deposition in histological sections after experimentation. To facilitate neuronal classification and obtain sustained neuronal activation after mustard oil application, only neurons with receptive fields on the hairy skin of the hindlimb were investigated. Neuronal activation to application of either innocuous brush or mustard oil stimuli to the peripheral receptive field was found in the majority of re- 


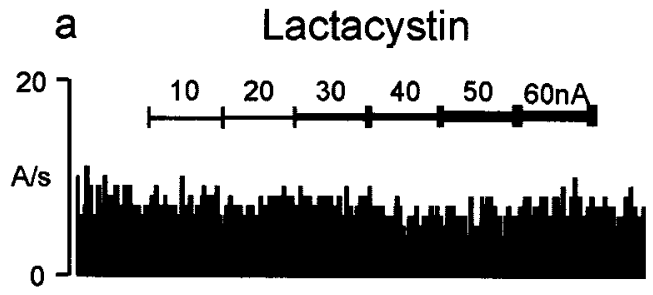

Brush
C Lactacystin

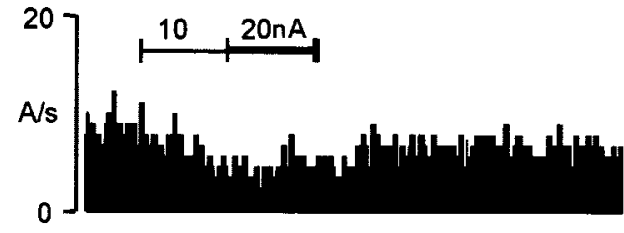

Brush no effect on brush-evoked activation of dorsal horn neuron cell firing rate, measured as action potentials per second $(A / s)$, but it caused a selective attenuation of mustard oil-evoked activation of dorsal horn neuron cell firing $(a, b)$. In contrast, in neuropathic animals, lactacystin reduced dorsal horn neuron firing evoked by application of brush, mustard oil, and cold stimuli to the neuronal receptive field area $(c-e)$. The bar (bottom right) indicates $1 \mathrm{~min}$ duration. Lines above the firing records indicate the duration of the drug application by ionophoresis, close to the recorded cell. This is measured in nanoamperes $(n A)$ of current used to eject the drug and was increased sequentially by $10 \mathrm{nA} \mathrm{ev-}$ ery 1-2 $\mathrm{min}$.

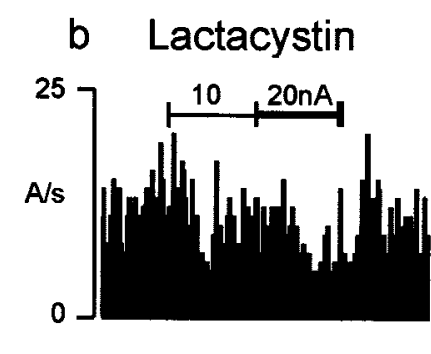

Mustard Oil d Lactacystin

e

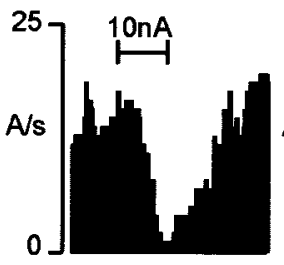

Mustard Oil

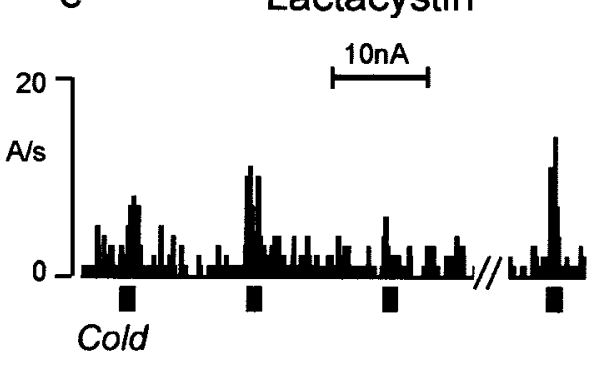

\section{Lactacystin}

$1 \mathrm{~min}$

Table 1. Effects of ionophoretically applied proteasome inhibitors on sensory responses of single dorsal horn neurons

$\%$ of stimulus-evoked response remaining

\begin{tabular}{|c|c|c|c|c|}
\hline \multirow[b]{2}{*}{ Drug } & \multirow[b]{2}{*}{ Condition } & \\
\hline & & Brush & Mustard oil & Cold \\
\hline \multirow[t]{9}{*}{ Lactacystin } & & $87.5 \pm 5.9$ & $58.6 \pm 7.1^{*}$ & \\
\hline & Naive & $(n=8)$ & $(n=7)$ & \\
\hline & & $(10-60 \mathrm{nA})$ & $(10-60 n A)$ & \\
\hline & & $79.2 \pm 1.6$ & $50.1 \pm 6.2^{*}$ & \\
\hline & Sham & $(n=3)$ & $(n=4)$ & \\
\hline & & $(50-60 \mathrm{nA})$ & $(10-40 \mathrm{nA})$ & \\
\hline & & $60.8 \pm 4.2^{*}$ & $34.1 \pm 5.1$ & $58.7 \pm 4.7^{*}$ \\
\hline & Neuropathic & $(n=4)$ & $(n=6)$ & $(n=3)$ \\
\hline & & $(20-60 \mathrm{nA})$ & $(20-40 \mathrm{nA})$ & $(10-30 \mathrm{nA})$ \\
\hline \multirow[t]{6}{*}{ MG-132 } & & $76.4 \pm 2.5$ & $57.1 \pm 8.8^{*}$ & \\
\hline & Naive & $(n=4)$ & $(n=4)$ & \\
\hline & & $(10-40 \mathrm{nA})$ & $(20-40 \mathrm{nA})$ & \\
\hline & & $66.4 \pm 5.4^{*}$ & $31.6 \pm 2.1^{*}$ & $48.3 \pm 7.4^{*}$ \\
\hline & Neuropathic & $(n=4)$ & $(n=7)$ & $(n=3)$ \\
\hline & & $(30-60 \mathrm{nA})$ & $(10-30 \mathrm{nA})$ & $(10-30 \mathrm{nA})$ \\
\hline
\end{tabular}

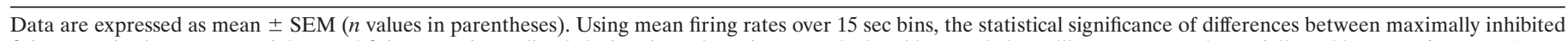

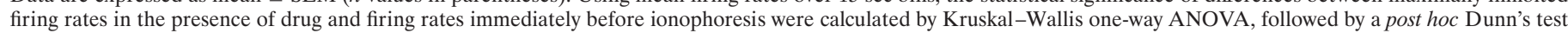

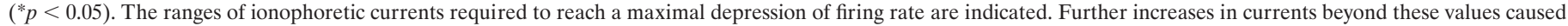
greater inhibition.

corded neurons in both normal and neuropathic animals showing peak behavioral reflex changes indicative of neuropathy. However, activation of neurons to cold stimuli $\left(4^{\circ} \mathrm{C}\right)$ were found only in neuropathic animals, which is in agreement with the observation that it is only neuropathic animals that develop a paw withdrawal response to cold water $\left(4^{\circ} \mathrm{C}\right)$. The spontaneous firing rates of neurons were low $(1-2 \mathrm{~Hz})$, and those in response to the stimuli were between 12 and $50 \mathrm{~Hz}$. For each neuron, in the majority of cases, the rate of firing in response to the different stimuli, before drug application, was within $15 \mathrm{~Hz}$. No significant change in activity was ever observed during control ejection of saline, $\mathrm{pH} 7.0$, or the vehicle $(0.5 \%$ aqueous dimethylformamide,
$\mathrm{pH} 4.5$ ) at currents up to $60 \mathrm{nA}$ for $5 \mathrm{~min}$. In naive animals, ionophoretic application of the proteasome inhibitors lactacystin or MG-132 caused partial inhibition of mustard oil-induced activity but no significant inhibition of brush-evoked activity (Fig. $1 a, b$; Table 1). The effects of lactacystin were similar in shamoperated animals (Table 1).

In neuropathic animals, however, the drugs caused a greater percentage reduction in all responses, inhibitory effects on brush responses now becoming statistically significant (Fig. $1 c-e$; Table 1). The de novo responses to cold, which appeared only in neuropathic animals, were also significantly inhibited by both lactacystin and MG-132. 

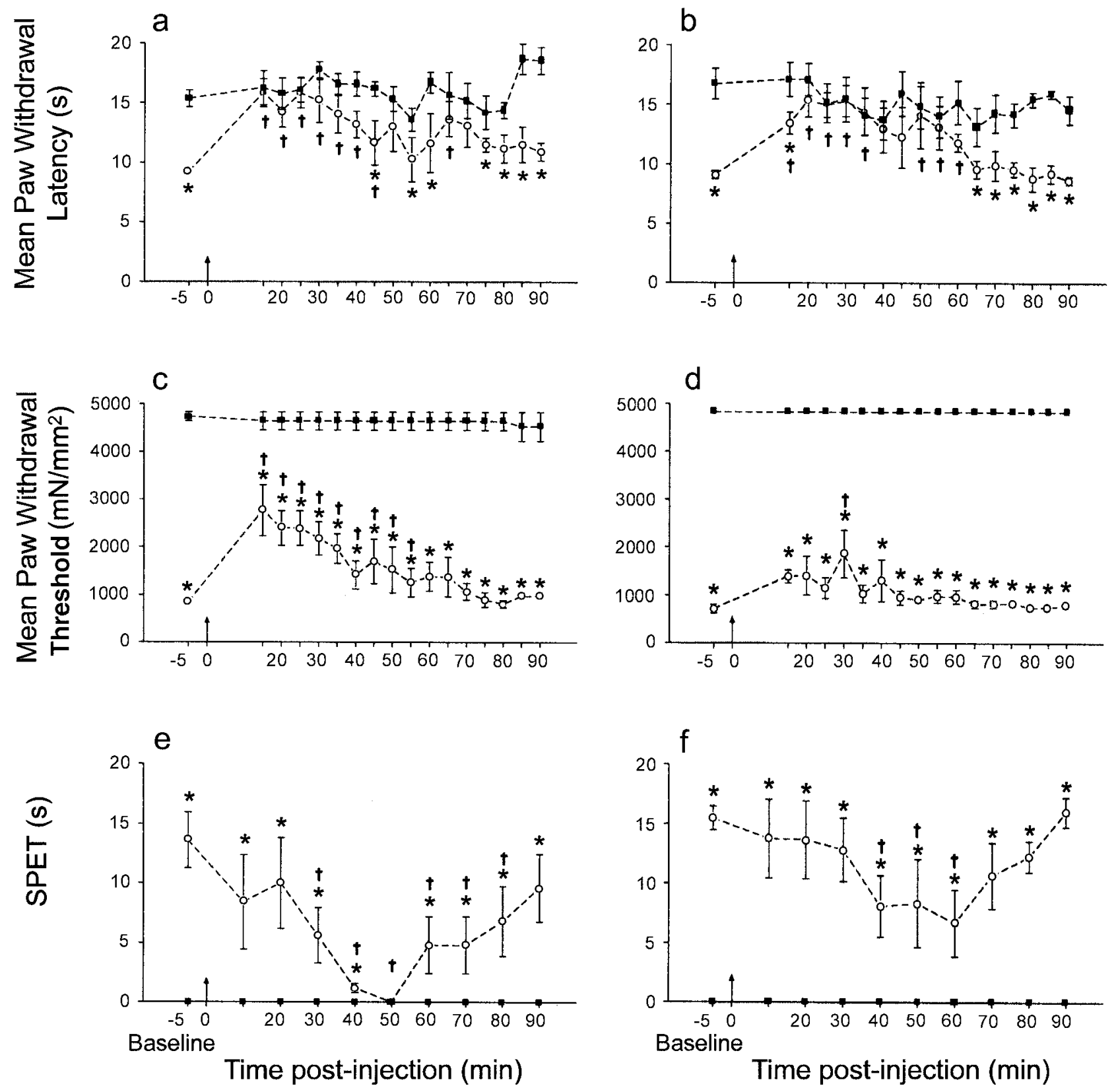

Figure 2. The effects of intrathecal administration of the proteasome inhibitors epoxomicin and MG-132 on reflex withdrawal responses to noxious thermal, innocuous mechanical, and innocuous cold stimuli in CCI rats. Data are presented as the mean paw withdrawal latency (in seconds) to noxious thermal stimulation $(a, b)$, paw withdrawal threshold in milliNewtons per millimeters squared $\left(\mathrm{mN} / \mathrm{mm}^{2}\right)$ to mechanical stimulation $(c, d)$, and suspended paw elevation time in seconds $[S P E T(s)]$ to cold water $\left(\right.$ at $\left.4^{\circ} \mathrm{C}\right)(e, f)$, before and after intrathecal administration of epoxomicin $(0.75 \mathrm{nmol} / 50 \mu \mathrm{l})(a-c)$ and MG-132 $(5 \mathrm{nmol} / 50 \mu \mathrm{l})(d-f)$, respectively (at arrow). Injection of vehicle $(0.5 \%$ dimethylformamide in saline) had no detectable effect on reflexes. Paw withdrawal latency from noxious heat and innocuous cold stimuli ipsilateral to CCI showed significant differences between pre-drug and post-drug administration values ( $(p<0.05$; one-way ANOVA, followed by a Dunnett's post hoc test). Significant differences between contralateral and ipsilateral paw are indicated $(* p<0.05$; Student's paired $t$ test). Paw withdrawal thresholds to mechanical stimulation ipsilateral to CCI showed significant differences between pre-drug and post-drug administration values ( ${ }^{\dagger} p<0.05$; Kruskal-Wallis one-way ANOVA, followed by a post hoc Dunn's test). Significant differences between contralateral and ipsilateral paw withdrawal thresholds are indicated $\left({ }^{*} p<0.05\right.$; Mann-Whitney $U$ test).

\section{Behavioral reflex changes after intrathecal administration of the proteasome inhibitors MG-132 and epoxomicin}

Intrathecal administration of the proteasome inhibitors MG-132 $(5 \mathrm{nmol} / 50 \mu \mathrm{l})$ and epoxomicin $(0.75 \mathrm{nmol} / 50 \mu \mathrm{l})$ in rats exhibiting peak neuropathic behavioral changes significantly reversed thermal hyperalgesia and mechanical and cold allodynia over a 90 min period (Fig. $2 a-c$ ). Control intrathecal administration of vehicle in CCI rats had no significant effect on baselines (Fig. $2 a-c)$. The intrathecal administration of proteasome inhibitors in naive rats had no significant effect on baseline values (data not shown).

\section{mRNA analysis by RT-PCR}

A semiquantitative RT-PCR approach was used for the screening of the UCH-L1 gene, the expression of which may be altered in a 


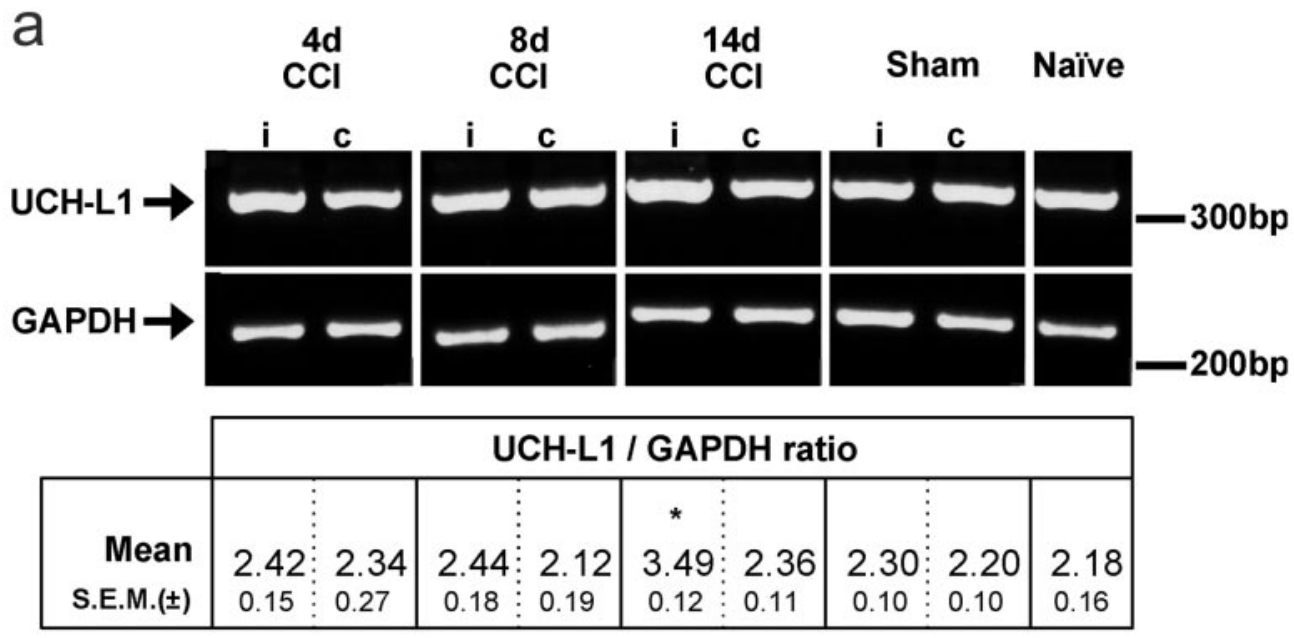

Figure 3. Determination of levels of mRNA for ubiquitin C-terminal hydrolase-L1 (UCH-L1). a, Relative abundance of UCH-L1 mRNA from spinal cord of CCI-treated rats as assessed by semiquantitative RT-PCR normalized to the signal obtained for the cellular housekeeping enzyme GAPDH. Densitometric analysis indicated that the relative UCH-L1 expression was similar in all conditions except in tissue ipsilateral to $\mathrm{CCI}$ at $14 \mathrm{~d}$, where expression was significantly greater than that in contralateral samples $\left({ }^{*} p<0.05\right.$ by paired Student's $t$ test; $n=3)$. Further analysis of the changes at $14 \mathrm{~d}$ after CCI was made by in situ methods. See $b$ and Table 2 for quantification data. $b$, In situ hybridization histochemistry to show UCH-L1 mRNA expression in lamina I of the rat medial dorsal horn. High-power, lightfield photomicrographs showing that expression of mRNA for UCH-L1 was higher ipsilateral to CCI after $14 \mathrm{~d}$, compared with contralateral tissue and naive dorsal horn. Scale bar, $100 \mu \mathrm{m}$.
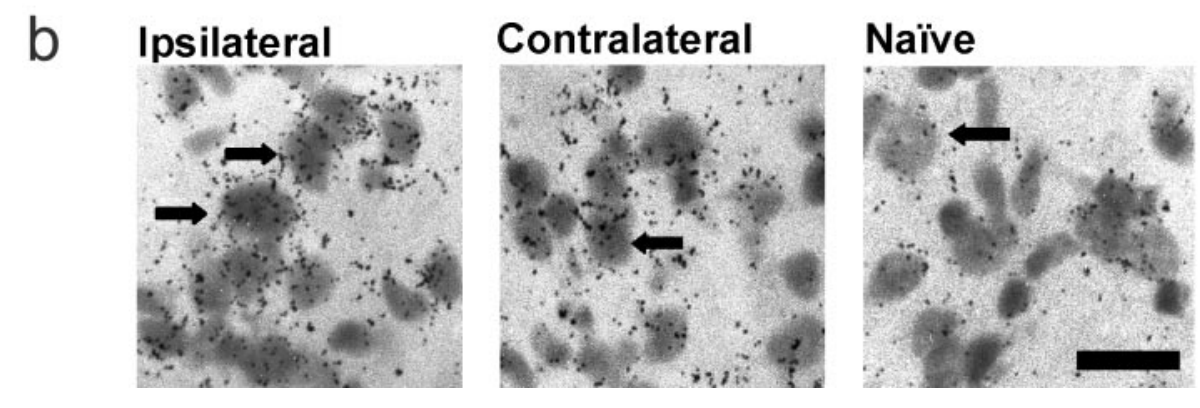

neuropathic state. Using the samples described previously, changes in the abundance of PCR product were normalized against GAPDH levels (Fig. 3a). GAPDH has previously been shown to be a stable and consistent housekeeping standard in cases of spinal cord and brain insult (Medhurst et al., 2000). RT-PCR performed on cDNA extracted from the spinal cord of rats using a PCR mixture containing primers to UCH-L1 and GAPDH generated two distinct PCR products of 324 and $292 \mathrm{bp}$, respectively (Fig. $3 a$ ). Analysis was performed on points in the PCR process at which exponential amplification was observed (whereby the abundance of both $\mathrm{UCH}$ and GAPDH is directly proportional to the level of respective mRNA in the sample). Concurrent PCR on samples for which reverse transcriptase was omitted produced no detectable amplification products (data not shown). A statistically significant increase (mean $+47 \%$ ) in the relative abundance of UCH-L1 mRNA was seen in the ipsilateral as compared with the contralateral spinal cord hemisection at $14 \mathrm{~d}$ (Fig. 3a). No significant changes in mRNA levels were observed between spinal cord sections of sham-operated or naive rats or ipsilateral to CCI in animals taken 4-8 d after nerve ligation.

\section{In situ hybridization histochemistry}

In accordance with the expression of $\mathrm{UCH}-\mathrm{L} 1$ protein throughout eukaryotic neural and neuroendocrine cell types and in line with its role in proteasomal functioning, the mRNA for rat UCH-L1 was distributed widely in spinal cord of both naive and neuropathic animals. After CCI, there were distinct changes in the expression of mRNA for UCH-L1 in the dorsal horn ipsilateral to nerve injury, compared with contralateral and naive values. The total number of neurons positively expressing mRNA for UCH-L1 was significantly increased in the ipsilateral dorsal horn, both medially in laminas I, II, and III and laterally in laminas I and II (Fig. 3b; Table 2). Silver grain density was significantly increased mediolaterally in laminas I, II, III, and V and laterally in laminas I, II, and III (Fig. 3b; Table 2). The significant increments in numbers of hybridizing cells and silver grain density ranged from $22-28$ to $17-41 \%$, respectively. Within the ventral horn of normal animals, labeling of motoneurons was especially intense but showed no significant change after CCI treatment (data not shown).

\section{Western blot analysis to monitor changes in protein levels of UCH-L1 after $\mathbf{C C I}$}

To determine whether the increase in UCH-L1 mRNA after CCI leads to an overall increase in the translation of its protein product, we performed Western blot analysis using an antibody specific to UCH-L1. Densitometry of immunoreactive bands revealed an ipsilateral increase of 27-31\% after CCI when compared with contralateral, sham-operated, and naive sample values. Samples were normalized in relation to levels of the established cellular housekeeper enzyme GAPDH, and values were expressed as the percentage relative GAPDH expression (Fig. 4a,b).

\section{Regulation of constitutive spinal cord PKA activity by the ubiquitin-proteasome system}

To obtain a readout of the function of the ubiquitin-proteasome system in spinal cord, we monitored the enzymatic activity of PKA, the activity of which is known to be regulated through 
Table 2. In situ hybridization histochemistry for UCH-L1 mRNA expression after CCI

\begin{tabular}{|c|c|c|c|c|c|c|}
\hline \multirow[b]{2}{*}{ Laminas } & \multicolumn{3}{|l|}{ Mediolateral } & \multicolumn{3}{|l|}{ Lateral } \\
\hline & $\mathrm{CCI} /$ ipsilateral & $\mathrm{CCI} /$ contralateral & Naive & $\mathrm{CCI} /$ ipsilateral & $\mathrm{CCI} /$ contralateral & Naive \\
\hline \multicolumn{7}{|c|}{ Mean number of hybridizing cells per section in spinal dorsal horn } \\
\hline LI & $35.5 \pm 1.2^{*}$ & $26.6 \pm 0.5$ & $25.9 \pm 1.1$ & $32.2 \pm 1.4^{*}$ & $24.4 \pm 1.1$ & $22.5 \pm 2.5$ \\
\hline LII & $35.2 \pm 1.8^{*}$ & $25.5 \pm 1.2$ & $25.5 \pm 1.4$ & $34.2 \pm 1.8^{*}$ & $28.2 \pm 2.1$ & $30.1 \pm 1.3$ \\
\hline LIII & $37.1 \pm 1.9^{*}$ & $30.5 \pm 1.2$ & $30.5 \pm 1.5$ & $36.5 \pm 3.1$ & $32.5 \pm 2.5$ & $35.6 \pm 2.2$ \\
\hline LIV & $42.2 \pm 2.2$ & $38.2 \pm 3.2$ & $38.8 \pm 3.4$ & $41.1 \pm 2.1$ & $40.5 \pm 1.4$ & $40.1 \pm 1.3$ \\
\hline LV & $38.9 \pm 1.4$ & $36.5 \pm 1.8$ & $37.5 \pm 2.2$ & $32.5 \pm 1.2$ & $32.1 \pm 0.6$ & $32.4 \pm 1.0$ \\
\hline \multicolumn{7}{|c|}{ Mean number of silver grains per cell } \\
\hline LI & $14.5 \pm 1.3^{*}$ & $10.3 \pm 0.8$ & $8.8 \pm 1.3$ & $12.4 \pm 1.3^{*}$ & $9.2 \pm 1.2$ & $8.8 \pm 0.4$ \\
\hline LII & $14.5 \pm 1.2^{*}$ & $11.6 \pm 0.8$ & $11.1 \pm 1.2$ & $13.6 \pm 1.2^{*}$ & $10.3 \pm 0.9$ & $10.0 \pm 0.6$ \\
\hline LIII & $29.8 \pm 2.3^{*}$ & $21.5 \pm 1.6$ & $19.2 \pm 2.3$ & $29.5 \pm 2.5^{*}$ & $24.8 \pm 2.1$ & $24.8 \pm 1.9$ \\
\hline LIV & $39.4 \pm 2.2$ & $35.1 \pm 2.1$ & $34.9 \pm 2.2$ & $35.8 \pm 2.2$ & $33.8 \pm 1.8$ & $32.0 \pm 1.9$ \\
\hline LV & $40.0 \pm 1.8^{*}$ & $31.0 \pm 2.1$ & $32.0 \pm 1.8$ & $39.2 \pm 3.1^{*}$ & $33.4 \pm 2.1$ & $32.0 \pm 2.0$ \\
\hline
\end{tabular}

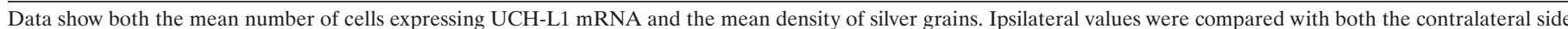

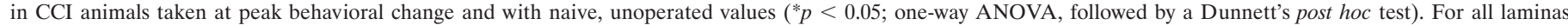
analyzed, there was no significant alteration in the relative expression of UCH-L1 mRNA when comparing contralateral CCI values with naive values.

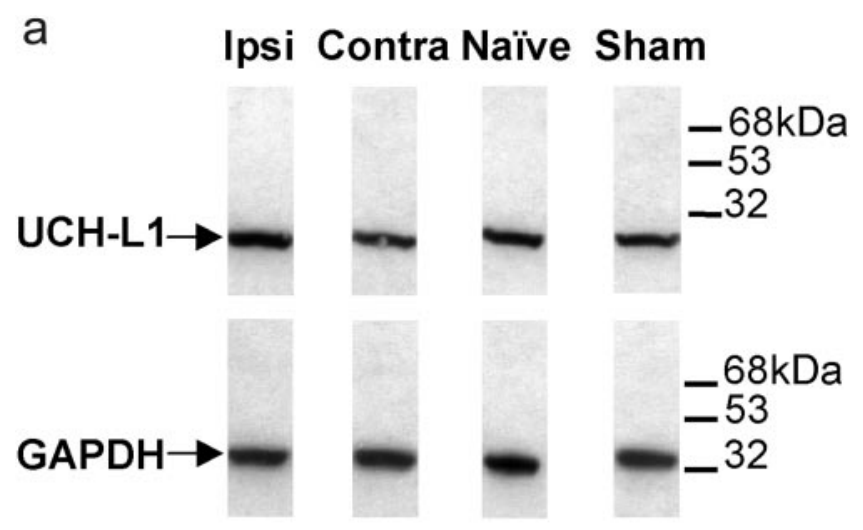

b

\begin{tabular}{|c|c|c|c|c|}
\cline { 2 - 5 } \multicolumn{1}{c|}{} & \multicolumn{4}{|c|}{$\begin{array}{c}\text { UCH-L1 immunoreactivity } \\
\text { (\% of GAPDH) }\end{array}$} \\
\cline { 2 - 5 } \multicolumn{1}{c|}{} & Ipsi & Contra & Naïve & Sham \\
\hline Mean & 112 & 85.4 & 88.2 & 85.7 \\
\pm SEM & $\pm 10.6^{*}$ & \pm 11.1 & \pm 3.0 & \pm 7.3 \\
\hline
\end{tabular}

Figure 4. Western blot analysis of the expression of UCH-L1 protein. Western blots of spinal cord samples from neuropathic, naive, and shamoperated rats. $a$ shows an increase in UCH-L1 protein expression ipsilateral (Ipsi) to CCI in neuropathic animals. No change from naive samples was observed in the sham-operated or contralateral side (Contra) of CCI samples. $b$ represents UCH-L1 expression as a percentage of GAPDH expression in terms of relative gray scale values after quantitative densitometry of ECL films. Data are presented as mean \pm SEM $\left(n=3 ;{ }^{*} p<\right.$ 0.05 , from control contralateral values; Student's paired $t$ test).

degradation of the regulatory subunits by the proteasome (Hegde et al., 1997; Chain et al., 1999). Degradation of regulatory subunits, leaving a relative excess of unrestrained catalytic subunits, is thought to lead to an elevated level of constitutive enzyme activity, which can be monitored by ex vivo enzyme assays (Roskoski, 1983). Table 3 shows that the fraction of PKA activity that was constitutive was significantly elevated in spinal cord ipsilat-
Table 3. Effects of the topical administration of the proteasome inhibitors epoxomicin and MG-132 on constitutive activation of protein kinase A induced by CCI

\begin{tabular}{lccl} 
& \multicolumn{3}{l}{$\begin{array}{l}\text { PKA activity of spinal cord homogenates } \\
\text { (constitutive activity as \% of total) }\end{array}$} \\
\cline { 2 - 4 } & & \multicolumn{3}{c}{ CCI } \\
\cline { 3 - 4 } Topical administration & Naive control & Ipsilateral & Contralateral \\
\hline Nil & $9.5 \pm 1.0$ & $15.7 \pm 1.2^{*}$ & $8.5 \pm 0.5$ \\
Vehicle & $7.9 \pm 0.8$ & $14.4 \pm 1.5^{*}$ & $9.1 \pm 0.5$ \\
Epoxomicin & $8.4 \pm 1.0$ & $9.9 \pm 0.8^{\dagger}$ & $8.1 \pm 1.1$ \\
MG-132 & - & $7.8 \pm 0.2^{\dagger}$ & $8.6 \pm 0.5$
\end{tabular}

After topical administration under anesthesia of $500 \mu \mathrm{l}$ of epoxomicin $(15 \mu \mathrm{M})$ MG-132 $(100 \mu \mathrm{M})$, or vehicle ( $0.5 \%$ dimethylformamide in saline), spinal segments (L3-L6) were removed and hemisected, before homogenization in cold buffer. Samples were assayed for authentic PKA $\left[{ }^{33} \mathrm{P}\right]$ phosphotransferase activity under constitutive and maximal cAMP-evoked conditions. Total authentic PKA activity was in the order of $100-200 \mathrm{pmol} \cdot \mathrm{min}^{-1} \cdot \mathrm{mg}^{-1}$ tissue under these conditions and similar between ipsilateral and contralateral CCI tissue. Values are expressed as means \pm SEM $(n=6-8)$. * indicates significantly greater than corresponding contralateral CCI values and naive control values $(p<0.05)$, by Wilcoxon test and Mann-Whitney $U$ test, respectively. ${ }^{\dagger}$ indicates significantly less than corresponding vehicle-treated tissue ipsilateral to CCI ( $p<0.05$ by Mann-Whitney $U$ test).

eral to CCI and that this elevation was prevented by local administration of the selective proteasome inhibitors epoxomicin and MG-132 to the spinal cord. This matches our other molecular and physiological data in suggesting that the activity of the ubiquitinproteasome system is elevated in response to nerve injury.

\section{Effects of proteasome inhibitor on $\mathrm{CCl}$-induced translocation of $\left[{ }^{3} \mathrm{H}\right]$ phorbol dibutyrate binding sites}

To investigate whether CCI-induced activation of PKC is altered by inhibition of the proteasome, we measured cytosol/membrane translocation of specific $\left[{ }^{3} \mathrm{H}\right]$ phorbol dibutyrate binding sites after topical administration of the proteasome inhibitor epoxomicin. In accordance with previous reports (Mao et al., 1993a,b), we found clear increases in specific binding of $\left[{ }^{3} \mathrm{H}\right]$ phorbol dibutyrate to the membrane rather than cytosolic fraction of tissue ipsilateral to CCI (Table 4). Smaller but still statistically significant increases were seen also on the contralateral side. Intrathecal administration of epoxomicin caused no detectable alteration in the translocation of $\left[{ }^{3} \mathrm{H}\right]$ phorbol dibutyrate binding sites (either 


\begin{abstract}
Table 4. Lack of effect of topical administration of the proteasome inhibitor epoxomicin on membrane translocation/activation of protein kinase $\mathbf{C}$
\end{abstract}

Specific $\left[{ }^{3} \mathrm{H}\right] \mathrm{PDBu}$ binding

(\% associated with membrane fraction)

\begin{tabular}{llll} 
& & \multicolumn{2}{c}{ CCI } \\
\cline { 2 - 4 } Topical administration & Naive control & Ipsilateral & Contralateral \\
\hline Vehicle & $24.0 \pm 3.7$ & $61.4 \pm 6.5^{*}$ & $46.0 \pm 4.9^{*}$ \\
Epoxomicin & $26.2 \pm 2.9$ & $61.0 \pm 4.8^{*}$ & $48.5 \pm 6.1^{*}$ \\
\hline
\end{tabular}

After topical administration of epoxomicin or vehicle under anesthesia (as in Table 3), spinal cord segments L3-L6 were removed and hemisected before homogenization in ice-cold buffer. Samples were assayed for membrane-bound and cytosolic specific $\left[{ }^{3} \mathrm{H}\right] \mathrm{PDB}$ binding sites. Total recovered specific binding was in the order of $6000 \mathrm{dpm}$ per sample aliquot and was similar in all conditions tested. Values are means \pm SEM $(n=5)$. * indicates significantly greater than naive control values $(p<0.05$ by Mann-Whitney $U$ test). PDBu, Phorbal dibutyrate.

ipsilateral or contralateral to CCI) under conditions in which it was shown to reduce the ipsilateral increase in constitutive activity of PKA (Tables 3, 4).

\section{DISCUSSION}

Injury in afferent nerves can elicit their sustained firing and result in phenotypic and functional changes both within dorsal root ganglia and in the dorsal horn of the spinal cord. The resulting state of central sensitization plays a key role in bringing about the hyperalgesia and allodynia, as well as sensitivity to cold, that characterize neuropathic pain states. We now provide evidence to suggest that the ubiquitin-proteasome system is important in the cellular mechanisms underlying neuropathic sensitization after CCI. The proteasome also appears to play a role in the normal spinal processing of noxious, but not innocuous, sensory stimuli. After CCI, previously innocuous stimuli such as brush and cold are perceived as noxious and correspondingly show sensitivity to blockade by proteasome inhibitors. Both the behavioral reflex studies and especially the electrophysiological experiments in animals with established CCI sensitization showed a rapid onset of activation of the proteasome inhibitors. Several structurally distinct proteasome inhibitors exhibited similar effects, suggesting that they are effective because of their actions on the proteasome. The rapidity of action suggests that ongoing degradation of a key signaling regulator (such as PKA regulatory subunits) is actively essential for the maintenance of established neuropathic sensitization. The contribution of the ubiquitin-proteasome system to sensitization was closely paralleled by increased expression (ipsilateral to nerve injury) of UCH-L1 at the level of RT-PCR, in situ hybridization (ISHH), and immunoblot. The steady-state elevation of UCH-L1 expression observed here at $14 \mathrm{~d}$ after CCI is less than the acute rise seen within $4 \mathrm{hr}$ after LTF in Aplysia (Hegde et al., 1997). This may relate in part to the higher basal levels of UCH-L1 in mammalian neurons (Wilkinson et al., 1989). Furthermore, the CCI sensitization model differs from LTF in that changes in spinal neuronal function develop slowly and are then maintained over many days. If optimal UCH-L1 activity is required for operation of the ubiquitin-proteasome system and this pathway plays a greater functional role after CCI (as demonstrated) then even small changes in UCH-L1 such as the increment of $\sim 30 \%$ seen in RT-PCR, ISHH, and immunoblot methods may be functionally significant. We do not know whether the level of UCH-L1 expression is rate limiting for proteasome function here, but if that is the case (as appears to be so in Aplysia
LTF), then the requirement for ongoing proteasome activity shown by the inhibitor results suggests that small increases might well result in functional change. The time course of the increase in UCH-L1 mRNA ipsilateral to CCI matched closely the development of behavioral reflex sensitization that we observed, being clearly established by $14 \mathrm{~d}$ after nerve ligation. No significant increases were detected at 4 or $8 \mathrm{~d}$ after surgery, times at which thermal hyperalgesia, mechanical allodynia, and cold allodynia were undetectable and showed $<25 \%$ development of maximal effect, respectively, in these experiments. UCH-L1 plays an essential role in the recycling of ubiquitin, which is necessary to maintain adequate rates of proteasome-mediated degradation of proteins. The regulatory subunits of PKA are an example of such a known proteasome target, and their degradation is thought to lead to the formation of constitutively active PKA. In accordance with our other data, elevated levels of constitutively active PKA were found in spinal cord ipsilateral to CCI, and this increase was reversed by acute local administration of a selective proteasome inhibitor. No changes were observed in the CCI-induced cytosol to membrane translocation of PKC, an alternative signal transduction mediator, which is not considered to be directly influenced by proteasome function.

Activity-dependent synaptic changes, associated with altered states of responsiveness and "synaptic memory," have been investigated in LTF in Aplysia (Bailey and Kandel, 1993) and in LTP in central mammalian neurons (Bliss and Collingridge, 1993). Although the precise nature and origin of these alterations differ, they may share a number of common features with the central sensitization that occurs within the spinal cord in response to chronic activation of nociceptive inputs.

Neuropathic sensitization is similar to other forms of repetitive input-induced sensitization in spinal cord (such as wind-up and inflammatory sensitization) in its dependence on NMDA receptor function (Mao et al., 1993a,b; Tal and Bennett, 1993). Although distinct neurochemical changes in these different pain states suggest that the mechanisms leading to NMDA receptor activation may differ, the NMDA receptor appears to be crucial to the sensitization phenomenon. It is not yet clear whether all forms of spinal sensitization rely on proteasome function as neuropathic sensitization does. However, the attenuation by proteasome inhibitors of both sub-acute mustard oil-evoked responses and neuropathic sensitization (which have in common a dependence on NMDA receptor-mediated events) (Heppenstall and Fleetwood-Walker, 1997) suggests that the role of the proteasome may relate closely to NMDA receptor activation. Whether the proteasome plays a role in processes leading to NMDA receptor activation or in events downstream of either the $\mathrm{Ca}^{2+}$ entry-mediated or adapter protein-mediated signaling of the receptor is not yet clear. Nevertheless, the proteasome clearly represents an interesting new target in neuropathic and other forms of pain.

PKA is implicated in spinal sensitization and pain (Cerne et al., 1993; Sluka, 1997). PKA may be activated downstream of receptors that lead to cAMP production (or downstream of $\mathrm{Ca}^{2+}$-mobilizing receptors, if $\mathrm{Ca}^{2+}$-activated isoforms of adenylate cyclase are present) and among many other targets is known to phosphorylate and activate both NMDA- and AMPA-type glutamate receptors (Greengard et al., 1991; Roche et al., 1996; Westphal et al., 1999). Although mutant mice with a targeted deletion of one of the PKA regulatory subunits did not show any attenuation of neuropathic sensitization (Malmberg et al., 1997), the fact that PKA catalytic activity is normally restrained by the 
presence of regulatory subunits makes this difficult to interpret. In the LTF model in Aplysia, PKA appears to play a key role in increased responsiveness, and substantial evidence indicates that an imbalance of PKA regulatory and catalytic subunits, mediated by proteasome degradation of the former, is a crucial factor (Hegde et al., 1993; Chain et al., 1999). This matches closely the proteasome-dependent generation of constitutively active PKA that we observed ipsilateral to CCI (Table 3). In the Aplysia model, expression of the homolog of UCH-L1 is rapidly increased in the facilitation paradigm (Hegde et al., 1997), again closely paralleling the observations here with neuropathic sensitization, except that the full development of the sensitized state here occurs over a more prolonged time period. An alternative pathway that is known to be subject to proteasome regulation is that of the transcription factor, nuclear factor $\kappa \mathrm{B}(\mathrm{NF}-\kappa \mathrm{B})$. NF- $\kappa \mathrm{B}$ exists in a latent form in unstimulated cells, complexed to the inhibitory protein, I- $\kappa \mathrm{B}$. Inflammation-associated molecules, such as cytokines, can induce $\mathrm{I}-\kappa \mathrm{B}$ phosphorylation, leading to its ubiquitination and degradation by the proteasome (Karin and Delhase, 2000). Dissociated NF- $\kappa \mathrm{B}$ can then regulate the expression of various target genes, including the inducible enzymes cyclo-oxygenase- 2 and nitric oxide synthase, adhesion molecules, cytokines, and neuropeptides (O’Neill and Kaltschmidt, 1997). Although NF- $\kappa \mathrm{B}$ expression decreases acutely after nerve injury (Doyle and Hunt, 1997), NF- $\kappa$ B immunoreactivity has been reported to increase within ipsilateral DRG neurons 2 weeks after nerve injury (Ma and Bisby, 1998), perhaps in response to cytokines and trophic factors secreted by non-neuronal cells during Wallerian degeneration. In cerebellar granule neurons, NF- $\kappa \mathrm{B}$ expression appears to be regulated by glutamate acting via NMDA receptors (Guerrini et al., 1995). In pilot experiments with intrathecal administration of the selective NF- $\kappa \mathrm{B}$ inhibitor parthenolide (Alexis) to CCI rats $(1.5 \mathrm{nmol} / 50 \mu \mathrm{l} 0.3 \%$ dimethylformamide in saline), we found no detectable change in behavioral responses to heat, cold, or mechanical stimuli (data not shown). This suggests that although certain proteasome targets like PKA may play an important role in neuropathic sensitization, others like the NF- $\kappa \mathrm{B} / \mathrm{I}-\kappa \mathrm{B}$ complex may not be important. Nevertheless, more extensive studies on these and other pathways will be necessary before it is clear how the proteasome plays out its key role in enabling neuropathic sensitization.

In conclusion, we have unexpectedly shown that proteasome inhibitors can selectively inhibit neuropathic sensitization, which is likely to underlie the development of chronic intractable pain after nerve injury. Importantly, proteasome inhibitors attenuate neuropathic allodynia without impairing normal sensory responses to low-intensity peripheral stimuli, a particularly advantageous therapeutic profile. Expression of a key enzyme in ubiquitin-proteasome function is increased in spinal dorsal horn ipsilateral to injury, as is the activity of a known target of the complex (PKA), which is expected to display deregulated constitutive activity after proteasome action. Proteasome-dependent activation of PKA in neuropathic sensitization closely parallels that in LTF in Aplysia. Proteasome inhibitors are under phase I trials as anti-cancer drugs (Lee and Goldberg, 1998). In many cases, advanced development of tumors leads to local inflammation and pressure trauma to afferent nerves, resulting in a neuropathic component to cancer pain. The present study predicts that in addition to any direct effect on cancer cells, proteasome inhibitors would exert a useful additional role in attenuating the central sensitization that leads to chronic hyperalgesia and allodynia.

\section{REFERENCES}

Bailey CH, Kandel ER (1993) Structural changes accompanying memory storage. Annu Rev Physiol 55:397-426.

Bennett GJ, Xie YK (1988) A peripheral mononeuropathy in rat that produces disorders of pain sensation like those seen in man. Pain 33:87-107.

Blackburn-Munro G, Fleetwood-Walker SM (1997) The effects of Na+ channel blockers on somatosensory processing by rat dorsal horn neurons. NeuroReport 8:1549-1554.

Blackburn-Munro G, Fleetwood-Walker SM (1999) The sodium channel auxiliary subunits beta 1 and beta 2 are differentially expressed in the spinal cord of neuropathic rats. Neuroscience 90:153-164.

Bliss TV, Collingridge GL (1993) A synaptic model of memory: longterm potentiation in the hippocampus. Nature 361:31-39.

Cameron AA, Cliffer KD, Dougherty PM, Garrison CJ, Willis WD, Carlton SM (1997) Time course of degenerative and regenerative changes in the dorsal horn in a rat model of peripheral neuropathy. J Comp Neurol 379:428-442.

Cerne R, Rusin KI, Randic M (1993) Enhancement of the $N$-methyl-Daspartate response in spinal dorsal horn neurons by cAMP-dependent protein kinase. Neurosci Lett 161:124-128.

Chain DG, Casadio A, Schacher S, Hegde AN, Valbrun M, Yamamoto N, Goldberg AL, Bartsch D, Kandel ER, Schwartz JH (1999) Mechanisms for generating the autonomous cAMP-dependent protein kinase required for long-term facilitation in Aplysia. Neuron 22:147-156.

Chung K, Lee BH, Yoon YW, Chung JM (1996) Sympathetic sprouting in the dorsal root ganglia of the injured peripheral nerve in a rat neuropathic pain model. J Comp Neurol 376:241-252.

Corbin JD (1983) Determination of the cAMP-dependent protein kinase activity ratio in intact tissues. Methods Enzymol 99:227-232.

Coux O, Tanaka K, Goldberg AL (1996) Structure and functions of the 20S and 26S proteasomes. Annu Rev Biochem 65:801-847.

Dickinson T, Mitchell R, Robberecht P, Fleetwood-Walker SM (1999) The role of VIP/PACAP receptor subtypes in spinal somatosensory processing in rats with an experimental peripheral mononeuropathy. Neuropharmacology 38:167-180.

Doyle CA, Hunt SP (1997) Reduced nuclear factor kappa B (p65) expression in rat primary sensory neurons after peripheral nerve injury. NeuroReport 8:2937-2942.

Fenteany G, Standaert RF, Lane WS, Choi S, Corey EJ, Schreiber SL (1995) Inhibition of proteasome activities and subunit-specific aminoterminal threonine modification by lactaystin. Science 268:726-731.

Greenberg SM, Castellucci VF, Bayley H, Schwartz JH (1987) A molecular mechanism for long-term sensitization in Aplysia. Nature 329:62-65.

Greengard P, Jen J, Nairn AC, Stevens CF (1991) Enhancement of the glutamate response by cAMP-dependent protein kinase in hippocampal neurons. Science 253:1135-1138.

Guerrini L, Blasi F, Denis-Donini S (1995) Synaptic activation of NFkappa B by glutamate in cerebellar granule neurons in vitro. Proc Natl Acad Sci USA 92:9077-9081.

Hegde AN, Goldberg AL, Schwartz JH (1993) Regulatory subunits of cAMP-dependent protein kinases are degraded after conjugation to ubiquitin: a molecular mechanism underlying long-term synaptic plasticity. Proc Natl Acad Sci USA 90:7436-7440.

Hegde AN, Inokuchi K, Pei W, Casadio A, Ghirardi M, Chain DG, Martin KC, Kandel ER, Schwartz JH (1997) Ubiquitin C-termina hydrolase is an immediate-early gene essential for long-term facilitation in Aplysia. Cell 89:115-126.

Heppenstall PA, Fleetwood-Walker SM (1997) The glycine site of the NMDA receptor contributes to neurokinin 1 receptor agonist facilitation of NMDA receptor agonist-evoked activity in rat dorsal horn neurons. Brain Res 744:235-245.

Hershko A, Ciechanover A (1998) The ubiquitin system. Annu Rev Biochem 67:425-479.

Hökfelt T, Zhang X, Wiesenfeld-Hallin Z (1994) Messenger plasticity in primary sensory neurons following axotomy and its functional implications. Trends Neurosci 17:22-30.

Johnson MS, Simpson J, Mitchell R (1996) Effect of phorbol 12,13dibutyrate on ligand binding, enzyme activity and translocation of protein kinase $\mathrm{C}$ isoforms in the alpha $\mathrm{T} 3-1$ gonadotrope-derived cell line. Mol Cell Biochem 165:65-75.

Kajimoto Y, Hashimoto T, Shirai Y, Nishino N, Kuno T, Tanaka C (1992) cDNA cloning and tissue distribution of a rat ubiquitin carboxyl-terminal hydrolase PGP 9.5. J Biochem (Tokyo) 112:28-32.

Karin M, Delhase M (2000) The I kappa B kinase (IKK), NF-kappa B: key elements of proinflammatory signaling. Semin Immunol 12:85-98.

Lee DH, Goldberg AL (1998) Proteasome inhibitors: valuable new tools for cell biologists. Trends Cell Biol 8:397-403.

Ma W, Bisby MA (1998) Increased activation of nuclear factor kappa B in rat lumbar dorsal root ganglion neurons following partial sciatic nerve injuries. Brain Res 797:243-254.

Malmberg AB, Brandon EP, Idzerda RL, Liu H, McKnight GS, Basbaum AI (1997) Diminished inflammation and nociceptive pain with pres- 
ervation of neuropathic pain in mice with a targeted mutation of the type I regulatory subunit of cAMP-dependent protein kinase. J Neurosci 17:7462-7470.

Mao J, Price DD, Hayes RL, Lu J, Mayer DJ, Frenk H (1993a) Intrathecal treatment with dextrorphan or ketamine potently reduces painrelated behaviors in a rat model of peripheral mononeuropathy. Brain Res 605:164-168.

Mao J, Mayer DJ, Hayes RL, Price DD (1993b) Spatial patterns of increased spinal cord membrane-bound protein kinase $\mathrm{C}$ and their relation to increases in $14 \mathrm{C}$-2-deoxyglucose metabolic activity in rats with painful peripheral mononeuropathy. J Neurophysiol 70:470-481.

Mayer DJ, Mao J, Holt J, Price DD (1999) Cellular mechanisms of neuropathic pain, morphine tolerance, and their interactions. Proc Natl Acad Sci USA 96:7731-7736.

Medhurst AD, Harrison DC, Read SJ Campbell CA, Robbins MJ, Pangalos MN (2000) The use of TaqMan RT-PCR assays for semiquantitative analysis of gene expression in CNS tissues and disease models. J Neurosci Methods 98:9-20.

O'Neill LA, Kaltschmidt C (1997) NF-kappa B: a crucial transcription factor for glial and neuronal cell function. Trends Neurosci 20:252-258.

Roche KW, O’Brien RJ, Mammen AL, Bernhardt J, Huganir RL (1996) Characterization of multiple phosphorylation sites on the AMPA receptor GluR1 subunit. Neuron 16:1179-1188.

Rock KL, Gramm C, Rothstein L, Clark K, Stein R, Dick L, Hwang D, Goldberg AL (1994) Inhibitors of the proteasome block the degradation of most cell proteins and the generation of peptides presented on MHC class I molecules. Cell 78:761-771.
Rolfe M, Chiu MI, Pagano M (1997) The ubiquitin-mediated proteolytic pathway as a therapeutic area. J Mol Med 75:5-17.

Roskoski R (1983) Assays of protein kinase. Methods Enzymol 99:3-6. Sin N, Kim KB, Elofsson M, Meng L, Auth H, Kwok BH, Crews CM (1999) Total synthesis of the potent proteasome inhibitor epoxomicin: a useful tool for understanding proteasome biology. Bioorg Med Chem Lett 9:2283-2288.

Sluka KA (1997) Activation of the cAMP transduction cascade contributes to the mechanical hyperalgesia and allodynia induced by intradermal injection of capsaicin. Br J Pharmacol 122:1165-1173.

Tal M, Bennett GJ (1993) Dextrorphan relieves neuropathic heatevoked hyperalgesia in the rat. Neurosci Lett 151:107-110.

Walters ET, Ambron RT (1995) Long-term alterations induced by injury and by 5-HT in Aplysia sensory neurons: convergent pathways and common signals? Trends Neurosci 18:137-142.

Westphal RS, Tavalin SJ, Lin JW, Alto NM, Fraser ID, Langeberg LK, Sheng M, Scott JD (1999) Regulation of NMDA receptors by an associated phosphatase-kinase signaling complex. Science 285:93-96.

Wilkinson KD (1997) Regulation of ubiquitin-dependent processes by deubiquitinating enzymes. FASEB J 11:1245-1256.

Wilkinson KD, Lee KM, Deshpande S, Duerksen-Hughes P, Boss JM, Pohl J (1989) The neuron-specific protein PGP 9.5 is a ubiquitin carboxyl-terminal hydrolase. Science 246:670-673.

Woolf CJ, Shortland P, Reynolds M, Ridings J, Doubell T, Coggeshall RE (1995) Reorganization of central terminals of myelinated primary afferents in the rat dorsal horn following peripheral axotomy. J Comp Neurol 360:121-134. 